\title{
Neonatal focal temporal lobe or atrial wall haemorrhagic infarction
}

\author{
P Govaert, K Smets, E Matthys, A Oostra
}

Department of
Neonatology
Gent University
Hospital
Gent
Flanders
Belgium
P Govaert
K Smets
E Matthys
Centre for
Developmental
Disorders
Gent
A Oostra
Correspondence to:
Dr Paul Govaert
Department of
Neonatology
Sophia Children's
Hospital
Dr Molewaterplein 603015
GJ Rotterdam
The Netherlands
Email:govaert@alkg.azr.nl
Accepted 26 April 1999

\begin{abstract}
Aims - To describe two variants of infarction within the temporal lobe, associated with local matrix bleeding and mild to moderate intraventricular haemorrhage. Methods-The files of 10 neonates, extracted from a sonographic study of $\mathbf{5 6 0}$ very low birthweight infants conducted between 1993 and 1997, were retrospectively examined.

Results-Seven lesions were located in the middle to posterior area of the temporal lobe, three others faced the atrium. All except two of those with a temporal site were VLBW infants with hyaline membrane disease. Except for one fatal case, intraventricular bleeding was mild to moderate. Computed tomograms or magnetic resonance imaging were used to illustrate the haemorrhagic nature of three lesions. Survivors of this so far undescribed entity who were followed up for more than 18 months did not have a uniform type of cerebral palsy but some scored in the low normal range on the Bayley Mental Development Index. One girl developed temporal lobe epilepsy. Conclusions-This pattern of injury seems to be one of venous infarction associated with temporal or para-atrial matrix haemorrhage. The temporal site fits the picture of venous infarction within the area drained by the inferior ventricular vein. A less constant lateral atrial vein, either draining into the basal or internal cerebral vein, is probably involved in the para-atrial lesion. Sonography may be the
\end{abstract}

only practical tool currently available for detection in life.

(Arch Dis Child Fetal Neonatal Ed 1999;81:F211-F216)

Keywords: temporal lobe; matrix haemorrhage; venous infarction; cerebral palsy

Hyperechoic patterns of perinatal injury in the temporal lobe include subarachnoid haematoma, ${ }^{12}$ basal subdural haematoma, ${ }^{34}$ infarction in the area of the posterior trunk of the middle cerebral artery, ${ }^{5}$ herpes encephalitis, ${ }^{6}$ vascular anomaly, ${ }^{7}$ tumour and abscess formation. A description of four preterm infants with focal cerebral infarction included an instance of mild intraventricular haemorrhage with ipsilateral temporal lobe paraventricular haemorrhagic infarction, the wedged shape of which suggested primary arterial stroke. ${ }^{8}$ Reference to bleeding within the germinal matrix underneath the neuroepithelium of the temporal lobe has only been made in necropsy studies. ${ }^{9}$ This report deals with two variants of infarction within the temporal lobe, recognised in life, and associated with local matrix bleeding and mild to moderate intraventricular haemorrhage.

\section{Methods}

Ten cases of unilateral focal temporal lobe hyperechogenicity form the basis of this report. They were extracted from a sonographic study carried out between 1993 and 1997, comprising 560 very low birthweight (VLBW) infants. Brain ultrasound scans in our unit were interpreted at the bedside by the neonatologist assigned to the infant and reviewed by one of

Table 1 Parenchymal temporal lobe haemorrhage associated with germinal matrix haemorrhage

\begin{tabular}{|c|c|c|c|c|c|}
\hline $\begin{array}{l}\text { Case } \\
\text { No }\end{array}$ & $\begin{array}{l}\text { Gestational } \\
\text { age }\end{array}$ & Clinical details & Side & $\begin{array}{l}\text { IVH } \\
\text { grade }\end{array}$ & Outcome \\
\hline \multicolumn{6}{|c|}{ Probable venous infarction within the area drained by the inferior ventricular vein } \\
\hline 1 & 27 & PROM, vaginal breech delivery, hypothermia, hypotension, grade 4 IRDS & Right & 4 & Early neonatal death (arrest of intensive care) \\
\hline 2 & 26 & $\begin{array}{l}\text { Third of quintuplet, vaginal breech delivery, grade } 4 \text { IRDS with pulmonary } \\
\text { emphysema, pneumothorax and chronic lung disease }\end{array}$ & Right & 2 & Late neonatal death \\
\hline 3 & 32 & Grade 3 IRDS & Left & 2 & Normal motor development at 7 months, MDI 105 \\
\hline 4 & 28 & $\begin{array}{l}\text { Second twin, emergency caesarean, grade } 4 \text { IRDS, pulmonary } \\
\text { hypertension, pulmonary emphysema, bilateral pneumothorax, open } \\
\text { ductus arteriosus (surgically clipped), chronic lung disease }\end{array}$ & Right & 2 & $\begin{array}{l}\text { Delayed milestones, mild cognitive dysfunction, no } \\
\text { cerebral palsy at } 42 \text { months }\end{array}$ \\
\hline 5 & 27 & $\begin{array}{l}\text { Grade } 3 \text { IRDS, transient posthaemorrhagic ventriculomegaly, urethral } \\
\text { valves with urosepsis }\end{array}$ & Left & 2 & $\begin{array}{l}\text { Transient lower limb hypertonia and mild cognitive } \\
\text { delay at } 18 \text { months (MDI 84) }\end{array}$ \\
\hline 6 & 40 & $\begin{array}{l}\text { Maternal diabetes insipidus, seizures on day } 2 \text {, right subacute temporal } \\
\text { cerebral and left cerebellar bleeding, no respiratory distress }\end{array}$ & Right & 2 & $\begin{array}{l}\text { Hypotonia and mild cognitive delay at } 34 \text { months } \\
\text { (MDI 88, Reynell language test at 5th centile) }\end{array}$ \\
\hline 7 & 28 & $\begin{array}{l}\text { PROM, early onset GBS septicaemia with hypotension, metabolic acidosis, } \\
\text { neutropenia; no IRDS, open ductus arteriosus }\end{array}$ & Right & 2 & Normal at 4 months \\
\hline \multicolumn{6}{|c|}{ Probable venous infarction within the area drained by the lateral atrial vein } \\
\hline 8 & 34 & $\begin{array}{l}\text { Enterococcal pneumonia (vertical transmission), pneumothorax, } \\
\text { pulmonary hypertension, chronic lung disease }\end{array}$ & Right & 2 & Mild left hemiparesis at 28 months, MDI 110 \\
\hline 9 & 34 & $\begin{array}{l}\text { Acceptor in a fetofetal transfusion, severe non-immune hydrops, persistent } \\
\text { hypoglycaemia, posthaemorrhagic hydrocephalus }\end{array}$ & Left & 2 & $\begin{array}{l}\text { Severe visual dysfunction, normal cognitive } \\
\text { dysfunction, poorly defined psychiatric disorder, } \\
\text { first epileptic insult at } 8 \text { years of age }\end{array}$ \\
\hline 10 & 31 & $\begin{array}{l}\text { Pre-eclampsia, intrauterine growth retardation, fetal distress } 3 \text { days before } \\
\text { caesarean section, no respiratory distress, lesion seen at } 1 \mathrm{~h} \text { of age }\end{array}$ & Right & 2 & No follow up yet \\
\hline
\end{tabular}




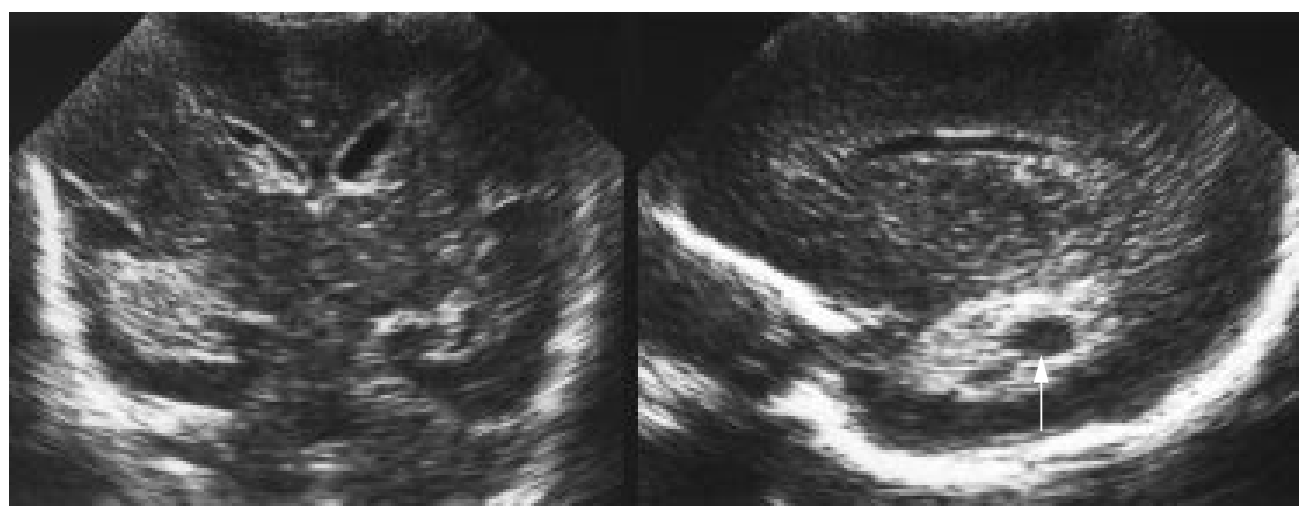

Figure 1 Case 2 on day 10: sections of the right temporal lobe through the coronal (left) and parasaggital (right) planes showing central clearing (arrow) adjacent to the outer wall of the ventricle.

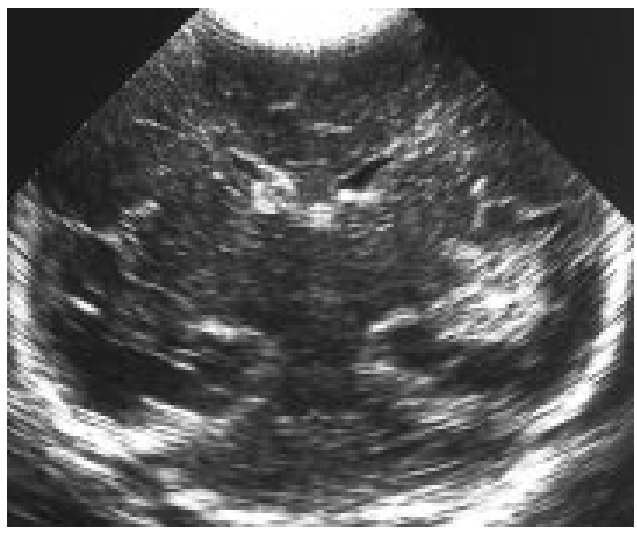

Figure 2 Case 3 on day 3: coronal section through the central area of the temporal lobe; corresponding to computed tomogram on day 8. This rounded hyperechoic focus with irregular inner margins was shown to be haemorrhagic on computed tomography (arrow); some of the clot, which went undetected by ultrasonography, is evident in the occipital horn (right).

the authors (PG). An ATL Ultramark 4 echograph with a $90^{\circ}$ mechanical sector scan and $7.5 \mathrm{MHz}$ emission frequency was used throughout the study. Scans were taken on admission and one to three more times in the first week, depending on the clinical situation. Thereafter weekly sonograms were taken.

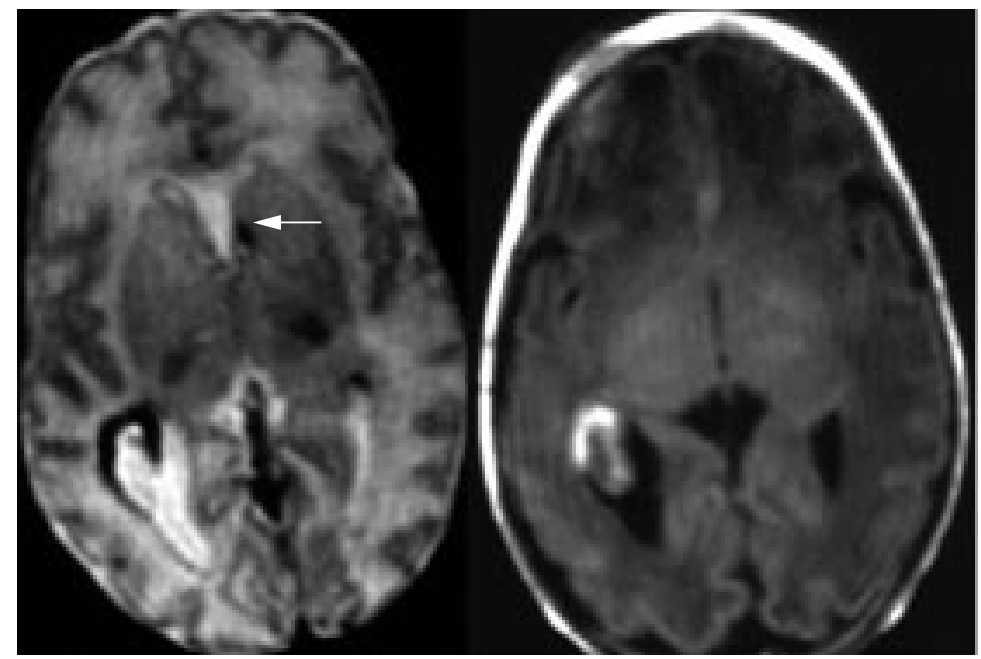

Figure 3 Case 7 on day 48; axial T2 (left) and T1 (right) weighted magnetic resonance images showing hyperintense (T1) amd hypointense (T2) old blood in a right temporal lobe hyperechoic focus detected on day 8. Note left subependymal haemorrhage (arrow) that was not detected by ultrasonography.

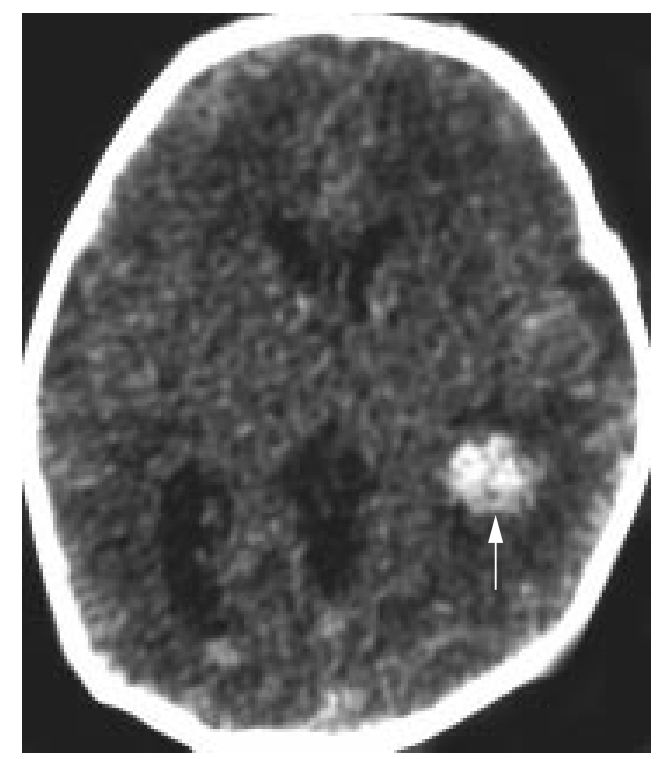

To be included, the sonographic lesion had to be unilateral, sited at least partly within the temporal lobe, sparing the temporal isocortex, be associated with intraventricular haemorrhage, and have a round or elliptoid shape in the coronal and parasagittal planes. The latter was important to ensure differentiation from pial arterial infarction (stroke), which would cause a wedge shaped hyperechoic lesion extending from the cortex to a few millimetres away from the ventricle wall.

Computed tomographic or magnetic resonance imaging confirmation of the haemorrhage was available for three infants.

Intraventricular haemorrhage (IVH) grade 2 was diagnosed when early neonatal sonograms suggested the presence of a limited amount of intraventricular blood (less than one third of the lateral ventricle cavity) and when serial sonographic evaluation in the late neonatal period sustained the diagnosis based on recognition of irregular clots, occipital horn hyperechogenicity, or dense ependymal lining. Grade 4 IVH referred to large fronto-parietal haemorrhagic parenchymal infarction associated with ipsilateral extensive ventricle bleeding. Parenchymal infarction was still visible on coronal sections through the glomus choroideum. 


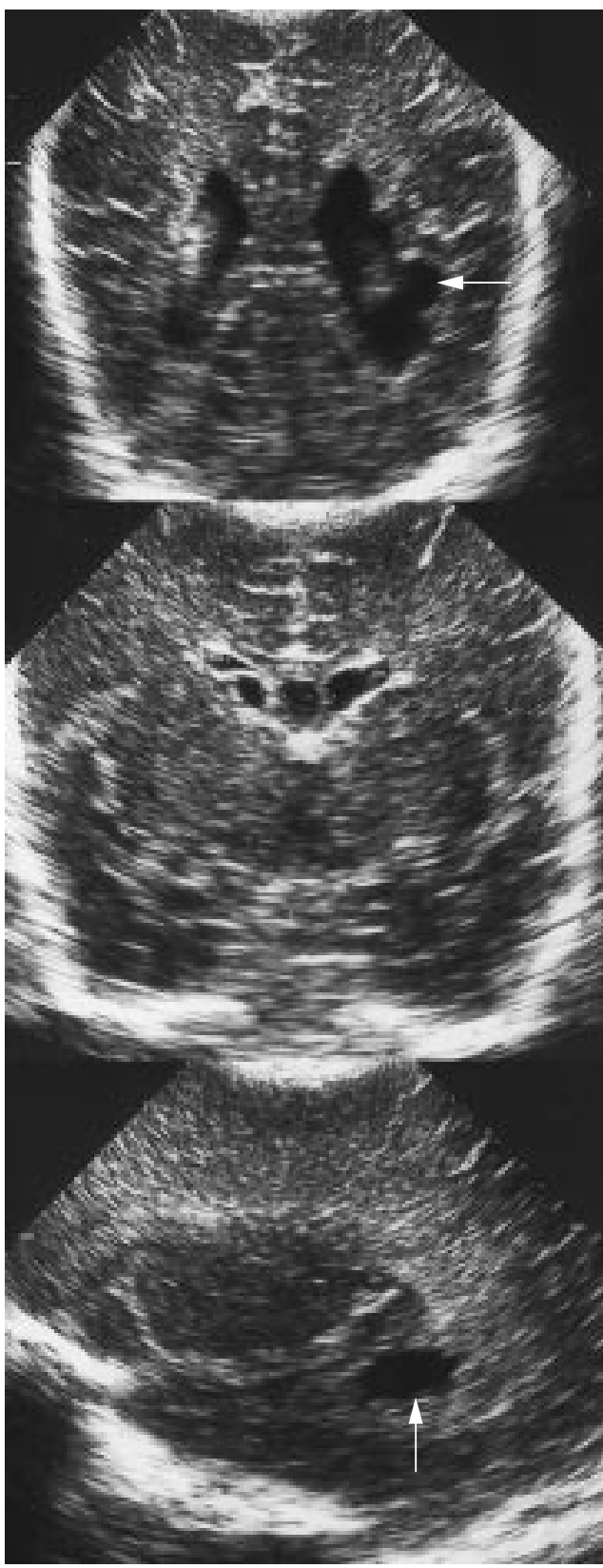

Figure 4 Case 5 on day 70: sections seen through the coronal (upper and middle panels) and left parasaggital planes (bottom): left posterior temporal hyperechoic focus has disappeared leaving a diverticle to the temporal horn (arrows) without hyperechoic margins. A contralateral subependymal germinolytic cyst of late postnatal origin can be seen.

Hyaline membrane disease grade 3 was diagnosed when the lungs appeared white with an air bronchogram and there was a fuzzy but recognisable cardiac silhouette. The latter was indistinct in grade 4 hyaline membrane disease.

Routine follow up at 4,7,12 and 24 months included Bayley Scales of Infant Development (Mental Development Index or MDI, the average of which was 100) and formal neurological examination. Venous brain anatomy was studied according to Newton and Potts. ${ }^{10}$

\section{Results}

The data from the 10 patients with temporal lobe infarction in association with intraventricular haemorrhage are presented in table 1 .
All but two had been ventilated (six VLBW infants) for hyaline membrane disease. Two died after intensive care had been withdrawn as a result of cerebral or respiratory problems with a poor prognosis.

Seven infants had a hyperechoic area in the middle to posterior area (on parasagittal section), superolateral (on coronal section) of the temporal lobe (fig 1). The haemorrhagic nature of the lesion was confirmed by early neonatal computed tomography in cases 3 (fig 2 ) and 6 , and by MRI in case 7 (fig 3 ). The hyperechoic focus in cases $2,3,7,6,4$ and 5 was followed with serial sonography up to the postnatal age of $15,34,48,50,110$ and 115 days, respectively. In cases $2-5$ and 7 the focus was homogeneously hyperechoic in the first week but with irregular elliptoid central dissolution in the course of the second postnatal week (fig 4). In case 6 a poorly distinguishable central nidus near the lateral and superior border of the temporal horn was already present by day 2 , suggesting antepartum onset. The entire hyperechoic area at first rested against the lateral ventricle, without adjacent healthy white matter. As such it was impossible to differentiate a paraventricular from an intraventricular clot on the early scans. Gradual regression of the hyperechoic area from its base against the ventricle suggested an image reminiscent of abscess. The clinical history was not compatible with cerebral abscess formation in any of these infants. A porencephalic aspect (diverticulated temporal horn) was seen in cases 4,5 , and 7 after day 50 (fig 4). Outcome data beyond 12 months were available for three infants. They shared a Bayley Mental Developmental Index in the (low) normal range and the absence of a specific motor disorder.

Three infants (cases 8-10) presented with a unilateral hyperechoic elliptoid focus facing the atrium of the lateral ventricle at the junction of the temporal, occipital, and parietal ventricle segments (fig 5). The sonographic course was identical with that described for the temporal lesion above. In case 7 the bright area persisted for at least 4 weeks and mimicked abscess formation. However, inflammatory signs subsided after 10 days of intravenous antibiotics, the cerebrospinal fluid grew no cultures, and the focus developed into a porencephalic diverticle. Both infants scored within the normal range for cognitive function on follow up, but one developed a mild motor hemisyndrome and the other epilepsy and severe visual dysfunction. Given discovery of the lesion one hour after birth in an unventilated VLBW infant (case 10) born by elective caesarean section, onset was probably antepartum.

\section{Discussion}

These neonates all exhibited unilateral temporal lobe infarction and intraventricular haemorrhage. Two anatomic variants were apparent. Seven children presented with infarction along the latero-superior border of the temporal horn in the middle to posterior region. The lesion extended beyond what could be expected to be matrix haemorrhage. With two exceptions, these were preterm infants with grades 3 or 4 


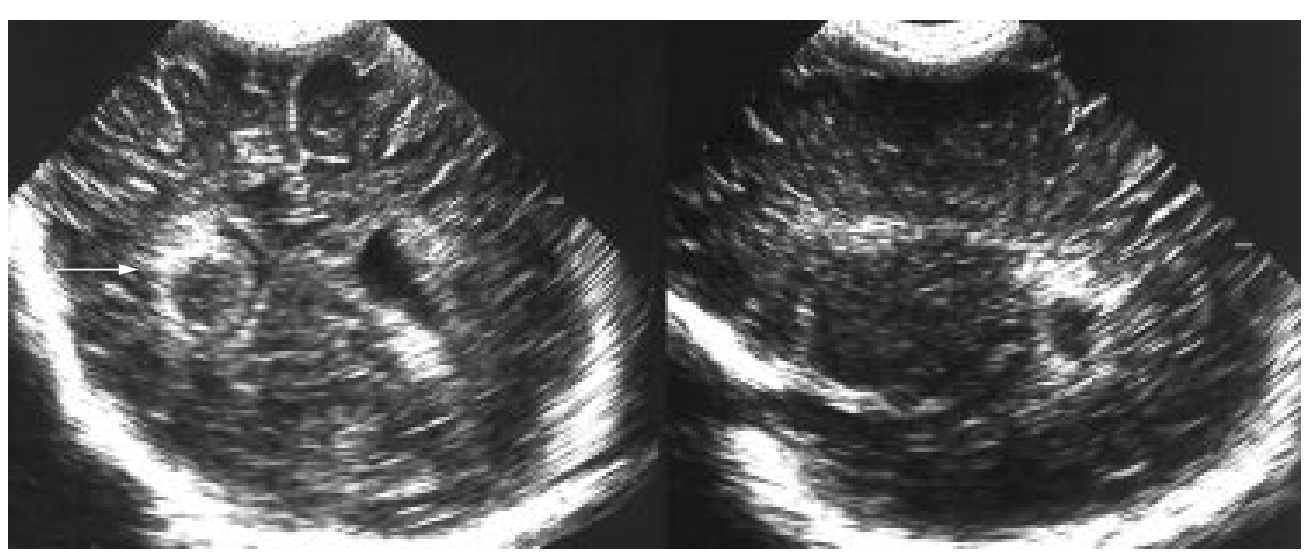

Figure 5 Case 8 on day 21: sections of the atrium through the coronal plane (left) and the right insular area through the parasaggital plane (right). The initially homogeneous para-atrial bright spot developed a central cavity, leaving a lateral and superior hyperechoic margin (arrow) which mimicked abscess formation.

hyaline membrane disease. The germinal matrix along the temporal horn in viable preterm infants is traversed by the inferior ventricular vein. ${ }^{10}$ This vein collects blood from the latero-superior border of the middle and posterior temporal horn and neighbouring white matter to its site of drainage in the basal vein of Rosenthal, near the anterior tip of the temporal horn (fig 6). ${ }^{11}$ Infarction due to occlusion of this vein by subependymal bleeding, would lead to a hyperechoic focus (figs 1,2, and 4). The inferior ventricular vein, the venous companion of the anterior choroidal artery, runs in the temporal portion of the stria terminalis and as such is the subependymal vein of the temporal horn. Its main tributaries are the inferior choroidal vein and the hippocampal venous plexus.

Bleeding into the temporal germinal matrix has been well documented. ${ }^{1213}$ Of 82 necropsy infants weighing under $2000 \mathrm{~g}$ at birth, $64(78 \%)$ had germinal matrix bleeding. ${ }^{9}$ The site of haemorrhage was caudothalamic in 62, temporal in 24 , and occipital in 22. The postmortem picture of an infant with a small temporal matrix haemorrhage, not detected by ultrasonography and therefore not included in the study, is shown in fig 7. This does not fit with the prevailing theory of a strong association with flow changes in the
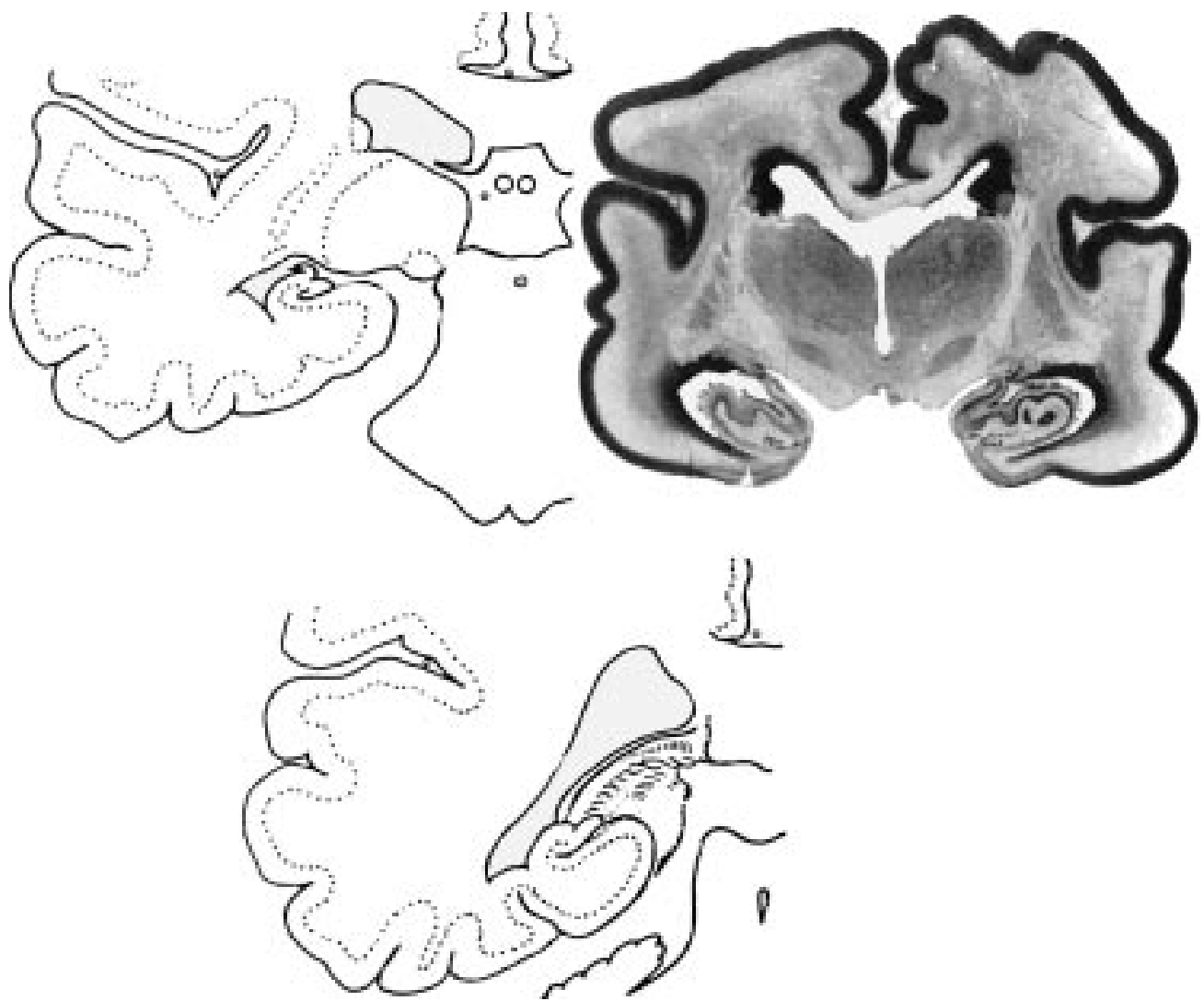

Figure 6 Illustration of coronal brain section at 26 weeks, ${ }^{12}$ showing germinal neuroepithelium along the lateral ventricle near the foramen of Monro and along the lateral wall of the temporal horn (arrow). Adapted from Newton and Potts. ${ }^{10}$ Top: coronal section through the right hemisphere at mid-temporal level; bottom : atrium at posterior temporal level. 

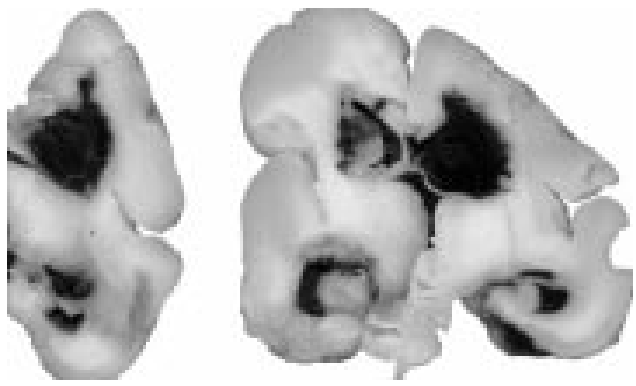

Figure 7 At 27 weeks of gestation, necropsy coronal section of classic fronto-parietal haemorrhagic venous infarction (probably in the region of the thalamo-striate veing) associated with a large subependymal haemorrhage near the caudo-thalamic groove; in the roof of the left temporal horn additional matrix bleeding is separate from the intraventricular clot (arrow).

thalamo-striate vein. The mode of genesis of paraventricular temporal infarction may be similar to parenchymal haemorrhage associated with caudo-thalamic groove matrix haemorrhage. In that setting focal hyperechoic areas correspond to venous infarction of frontal and parietal periventricular white matter, to some extent. ${ }^{14-17}$ Temporal (subinsular) venous infarction is not mentioned in these reports. The natural course of infarction of the area drained by the inferior ventricular vein, with central cavitation in the latter part of the second week after discovery, and ultimate development of a porencephalic diverticle, is akin to the evolution of fronto-parietal venous infarcts. ${ }^{17}$ Variation in size and location within the temporal lobe may accord with variation in recruitment of venous tributaries, but also in venous anatomy.

Three infants presented with unilateral infarction lateral to the atrium. Periventricular white matter in that area is drained through lateral atrial veins to the basal vein, together with the internal cerebral vein, the major tributary of the great cerebral vein of Galen. The lateral atrial veins follow a trajectory in the roof of the posterior part of the temporal horn, where they can be embedded in the germinal matrix (fig 6). ${ }^{10}$ Lateral and medial atrial veins may join to form a common stem draining into the internal cerebral or basal veins. Deep cerebral venous thrombosis, starting from the superior sagittal sinus and spreading to the vein of Galen, may engender thrombosis of the basal or internal cerebral veins. Basal vein thrombosis may appear as a para-atrial haemorrhagic infarction similar to the cases described here. With internal cerebral vein thrombosis, haemorrhage into the thalamus and caudate nucleus head is often seen. ${ }^{18}$ With this so-called thalamo-caudato-ventricular bleeding, limited intraventricular haemorrhage follows bleeding into the germinal matrix or choroid plexus. This suggests that para-atrial infarction may result from occlusion of the lateral atrial vein, either by primary thrombosis or secondary to compression by temporal matrix haemorrhage. In and around the caudothalamic groove subependymal haemorrhage venous thrombi have been found in preterm infants at necropsy, ${ }^{12}{ }^{19}$ although it is not clear whether haemorrhage follows or precedes small vein thrombosis.

Grey scale and colour Doppler flow imaging may permit serial measurement of deep venous flow velocities. ${ }^{20}{ }^{21}$ Direct observation of the impact of respiratory pressure changes in ventilated preterm infants still has to be made, but circumstancial evidence is strong enough to establish a link between respiratory distress and matrix bleeding near the caudate head. ${ }^{22-25}$ The same association may exist for the temporal lobe matrix.

Both temporal periventricular lesions described above have to be differentiated from tumour, vascular anomaly, ${ }^{7}$ abscess formation, venous infarction with transverse sinus thrombosis, ${ }^{26}$ herpes encephalitis, ${ }^{67}$ stroke within the truncus posterior of the middle cerebral artery ${ }^{57-31}$ or within the posterior cerebral artery, ${ }^{52-35}$ temporal periventricular leukomalacia ${ }^{36}$ and post-asphyxial watershed infarction. ${ }^{37}$

Our developmental data are insufficient to draw firm conclusions. Infarction in the temporal lobe does not seem to predict a definite motor disorder (one child with a contralateral motor hemisyndrome among five survivors follow ed up beyond 1 year of age). The lesions or associated conditions may lead to cognitive and visual dysfunction, without lowering the developmental quotient below. Special attention should be paid to memory and language development in addition to auditory and visual perception. The prevalence of temporal lobe epilepsy should be monitored for several years: these lesions may be one of the many causes of the mesial variant. ${ }^{38}$

A hyperechoic focus in the temporal lobe deserves careful investigation. As this study shows, serial sonography may suffice to differentiate between disease patterns in sick neonates. Confirmation of the haemorrhagic nature (with computed tomography or MRI) will increase diagnostic strength. Postmortem confirmation is warranted, with a special focus on the link between matrix haemorrhage and venous occlusion within the area of the basal vein of Rosenthal.

1 Govaert P, Leroy J, Caemaert J, Wood B. Extensive neonatal subarachnoid haematoma. Am f Dis Child 1992; 146:6356.

2 Govaert P, Bridger J, Wigglesworth J. Nature of the brain lesion in fetal allo-immune thrombocytopenia. Dev Med Child Neurol 1995;37:485-95.

3 Romodanov AP, Brodsky YS. Subdural hematomas in the newborn. Surgical treatment and results. Surg Neurol 1987;28:253-8

4 Govaert P, Vanhaesebrouck P, De Praeter C. Traumatic neonatal intracranial bleeding and stroke. Arch Dis Child 1992;67:840-5.

5 Fujimoto S, Yokochi K, Togari H, et al. Neonatal cerebral infarction: symptoms, CT findings and prognosis. Brain Develop 1992;14:48-52.

6 Cleveland RH, Herman TE, Oot RF, Kushner DC. The evolution of neonatal herpes encephalitis as demonstrated by cranial ultrasound with CT correlation. Am F Perinatol 1987;4:215.

7 Couture A, Veyrac C, Baud C. Echographie cérébrale du foetus au nouveau-né. Imagerie et hémodynamique. Montpellier: Sauramps Médical, 1994.

8 De Vries LS, Regev R, Connell JA, Bydder GM, Dubowitz LMS. Localized cerebral infarction in the premature infant: an ultrasound diagnosis correlated with computed tomography and magnetic resonance imaging. Pediatrics 1988;81:36-40.

9 Paneth N, Rudelli R, Kazam E, Monte W. Brain damage in the preterm infant. Clinics in Developmental Medicine
1994;131:71-3. 
10 Newton TH, Potts DG. Radiology of the skull and brain Volume 2.In: Angiography. Deep supratentorial veins. St Volume 2.In: Angiography. D
Louis: CV Mosby, 1974:1903.

11 Fees-Higgins A, Larroche J-C. Le développment du cerveau foetal humain. Atlas anatomique. Paris: Masson, 1987.

12 Padget DH. The cranial venous sytem in man in reference to development, adult configuration and relation to the arteries. Am F Anat 1956;98:307-56.

13 Marin-Padilla M.. Developmental neuropathology and impact of perinatal brain damage. I: Hemorrhagic lesion of neocortex. F Neuropathol Exp Neurol 1996;55:758-73.

14 Schwartz P. Geburtsschäden bei Neugeborenen. Jena: Gustav Fisher Verlag, 1964.

15 Guzetta F, Shackelford GD, Volpe S, Perlman JM, Volpe JJ. Periventricular intraparenchymal echodensities in the premature newborn: critical determinant of neurologic outcome. Pediatrics 1986;78:995-1006.

16 Blackman JA, McGuiness GA, Bale JF, Smith WL. Large postnatally acquired porencephalic cysts: unexpected postnatally acquired porencephalic cysts: unexpected

17 Perlman JM, Rollins N, Burns D, Riser R. Relationship between periventricular intraparenchymal echodensities and germinal matrix- intraventricular hemorrhage in the very low birth weight neonate. Pediatric

18 Rademaker KJ, Groenendaal F, Jansen GH, Eken P, de Vries LS. Unilateral haemorrhagic parenchymal lesions in the preterm infant: shape, site and prognosis. Acta Paediatr Scand 1994;83:602-8.

19 Govaert P, Achten E, Vanhaesebrouck P, De Praeter C, Van Damme J. Deep cerebral venous thrombosis in thalamoventricular hemorrhage of the term newborn. Pediat Radiol 1992;22:123-7.

20 Towbin A. Central nervous system damage in the human fetus and newborn infant. Am f Dis Child 1970;119: 52942 .

21 Winkler P, Helmke K. Duplex-scanning of the deep venous drainage in the evaluation of blood flow velocity of the cerebral vascular system in infants. Pediatr Radiol 1989;19:79ebral

22 Taylor

aylor GA. Intracranial venous system in the newborn evaluation of normal anatomy and flow characteristics with color doppler US. Radiology 1992;183:449-52.

23 deLemos RA, Tomasovic JJ. Effects of positive pressure ventilation on cerebral blood flow in the newborn infant. Clin Perinatol 1978;5:395.

24 Archer LNJ, Evans DH, Paton JY, Levene MI. Controlled hypercapnia and neonatal cerebral artery Doppler ultrasound waveforms. Pediatr Res 1986;20:218-21.
25 Nijima S, Shortland DB, Levene MI, Evans DH. Transient hyperoxia and cerebral blood flow velocity in infants born prematurely and at full term.. Arch Dis Child 1988;63:1126-30

26 Perlman JM, Volpe JJ. Are venous circulatory abnormalities important in the pathogenesis of hemorrhagic and/or ischemic cerebral injury? Pediatrics 1987;80:705-11.

27 Govaert P. Cranial haemorrhage in the term newborn infant. Clinics in Developmental Medicine 1993; 29:78-85.

28 Billard C, Dulac O, Diebler C. Ramollissement cérébral ischémique du nouveau-né. Arch Fr Pédiatr 1982; 39:67783.

29 Mannino FL, Trauner DA. Stroke in neonates. F Pediatr 1983;102:605-10

30 Clancy R, Malin S, Larague D, Baumgart S, Younkin D. Focal motor seizures heralding stroke in full-term neonates. Am f Dis Child 1985;139:601-6.

31 Wulfeck BH, Trauner DA, Tallal PA. Neurologic, cognitive, and linguistic features of infants after early stroke. Pediatr Neurol 1991;7:266-9.

32 Vargha-Khadem F, O'Gorman AM, Watters GV. Aphasia and handedness in relation to hemispheric side, age at injury and severity of cerebral lesion during childhood. injury and severity of cere $1985 ; 108: 677-96$.

33 De Vries LS, Eken P, Beek E, Groenendaal F, Meiners LC. The posterior fontanelle : a neglected acoustic window. Neuropediatrics 1995;27:101-4.

34 Remillard GM, Ethier R, Andermann F. Temporal lobe epilepsy and perinatal occlusion of the posterior cerebral artery. Neurology 1974;24:1001-9.

35 Levy SR, Abroms I-F, Marshall PC, Rosquete EE. Seizures and cerebral infarction in the full-term newborn. Ann Neurol 1985;17:366-70.

36 von Cramon DY, Hebel N, Schuri U. Verbal memory and learning in unilateral posterior cerebral infarction. A report of 30 cases. Brain 1988;111:1061-77.

37 Banker BQ, Larroche J-C. Periventricular leukomalacia of infancy:a form of neonatal anoxic encephalopathy. Arch Neurol 1962;7:386-410.

38 Volpe JJ, Herscovitch P, Perlman JM, Kreusser KL, Raichle HE. Positron emission tomography in the asphyxiated term newborn : parasagittal impairment of cerebral blood flow. Ann Neurol 1985;17:287-96. 